\title{
Review on uncertainty of the first-flush phenomenon in diffuse pollution control
}

\author{
Abdullah Al Mamun ${ }^{1}$ (D) Shahriar Shams ${ }^{2} \cdot$ Md. Nuruzzaman $^{3}$
}

Received: 14 October 2018 / Accepted: 23 December 2019 / Published online: 6 January 2020

(C) The Author(s) 2020

\begin{abstract}
Several definitions and criteria of the first-flush are being used to assess and control the nonpoint source (diffuse) pollution. The common consensus is that the first-flush is generally noticed in the small catchments (e.g. $<10$ ha) of regular shapes. It is also considered that $80 \%$ of the pollution load can be captured by capturing $30 \%$ of the runoff volume, which is assumed to be due to first-flush of the storm event. However, such phenomenon is uncertain in the considerably large catchments, principally due to the dilution and delay in transport of the pollutant. This paper critically examines the 'first-flush' phenomenon in controlling diffuse pollution based on various studies conducted by the researchers. Based on the review, it can be inferred that the first-flush may be an effective criterion for sizing on-site treatment facilities for small catchments (with similar dimensions of length and width), from where the runoff is expected to reach the treatment facility (roughly) at the same time. However, for the large and elongated catchments with an area covering more than $10 \mathrm{ha}$, a huge volume of storm runoff needs to be captured that would make the treatment system large or less effective. As such, for the community and regional facilities; the presence of the first-flush needs to be confirmed based on the sampling and analysis of data collected from several storm events of different durations and intensities. Therefore, the use of the first-flush phenomenon should not be applied for the design of storm runoff treatment facility in large drainage system (say $>10 \mathrm{ha}$ ) without on-site monitoring being conducted. However, it is also recommended to come up with a simplistic approach of designing the best management practices (BMPs) to capture and treat certain depth of the initial storm runoff (e.g. first $20 \mathrm{~mm}$ ), which will help reduce the effect of nonpoint source (NPS) pollution.
\end{abstract}

Keywords The first-flush $\cdot$ Diffuse pollution $\cdot$ On-site facilities $\cdot$ Runoff pollution $\cdot$ Storm runoff

\section{Introduction}

Water resources are polluted due to pollution from various sources (both from the point and nonpoint sources). The contribution of annual pollution to the water bodies depends on the type of landuse in the urban or rural developments. Studies have reported that annual pollution load due to the

Abdullah Al Mamun

mamun@iium.edu.my

1 Department of Civil Engineering, Faculty of Engineering, International Islamic University Malaysia (IIUM), Kuala Lumpur, Malaysia

2 Civil Engineering Programme Area, Universiti Teknologi Brunei (UTB), Gadong BE 1410, Brunei Darussalam

3 Department of Civil Engineering, Bangladesh Army University of Engineering and Technology (BAUET), Qadirabad, Natore 6431, Bangladesh diffuse pollution sources is substantial (Mamun et al. 2014; Torno 1984) and certain pollutants (e.g. suspended solids, chemical oxygen demand, salts, etc.) are discharged more from the diffuse sources due to storm runoff. As such, the need for diffuse pollution control deemed to be necessary to protect the water resources. However, the volume of storm runoff is huge compared to the wastewater produced from the urban sources. Therefore, the concept of the 'first-flush' separation from the total runoff hydrograph was developed among the practitioners and authorities such that significant amount of diffuse pollutants could be isolated for treatment instead of dealing with the whole volume of runoff during each storm event. The characteristics of water pollution during rainy days largely depend on the type of urban drainage systems (separate or combined sewer) infiltration of storm runoff, sewage overflows, etc. (Novotny and Olem 1994). A common mitigation strategy often recommended for reduction and management of stream flow and pollution is the 
result of either storage ponds or detention basins. The storage facilities are typically used to capture the initial volume (few centimetres) of the storm runoff. This idea is found on the perception that the initial part of the storm runoff is likely to be the most polluted, a concept known as the 'first-flush' (FF).

The first-flush phenomenon has been studied for several different contributing components of urban storm runoff, including rainwater, roof runoff, surface runoff, discharge of separate systems, discharge of combined systems and flow of receiving waters. In light of the diverse definitions of the phenomenon, and the different sampling strategies (locations) and methods of data collection often employed, it is difficult to compare the results and often very different conclusions derived from various studies on the first-flush phenomenon in urban runoff. Therefore, the main objective of this review paper was to gather information on various first-flush concepts followed in various parts of the world and critically comment on the concepts. Based on the information available in the literature, this paper also made a recommendation for more efficient use of the first-flush concept for better control of storm runoff-related pollution.

\section{Concept of first-flush}

A first-flush is explained as the occurrence of high pollutant concentration or that occurs within the initial stage of a rain event. Depending on the rainfall-runoff characteristics, it can be considered as the initial portion of the storm or a particular volume of runoff. According to Vorreiter and Hickey (1994), if the runoff pollution is higher than the dry day concentration of the pollutograph, the occurrence of the first-flush can be considered. The pollution loading characteristics of an urban runoff can be categorized as advanced, lagging, mixed or uniform, as illustrated in Fig. 1 (Griffin et al. 1980). The traditional approach to determine the existence of a first-flush is to plot flow versus pollutant load produced for a single event (Bertrand-Krajewski et al. 1998). A flushing action is considered as existing, if the contaminant

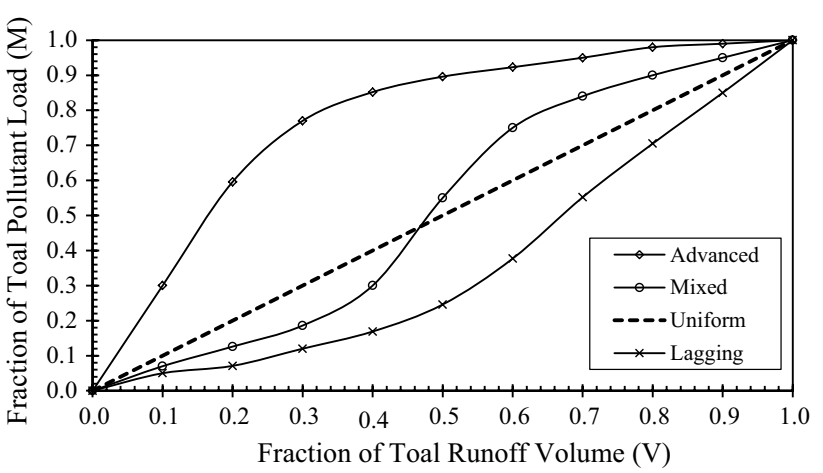

Fig. 1 Typical loading characteristics of runoff loadings yield a curve which lies above a $45^{\circ}$ diagonal line passing through the origin, because the first $50 \%$ of the runoff has transported a greater proportion of pollutant mass.

\section{Previous studies}

The presence of the first-flush occurrence has been investigated to study the effects of rainfall intensity, storm duration, inter-event dry period, on runoff from the roofs, pavements, parking lots, drains, etc. (Table 1). Besides various classifications of the first-flush, and different sampling approaches, ways of data collection, it is tough to relate the results inferences derived from several studies. To determine the occurrence of the first-flush, it is needed to know the spreading of the contaminant load against runoff volume. This kind of work requires detailed sampling of runoff to establish reliable relation between pollutant mass and runoff volume. It will enable to choose the suitable methodology for the nonpoint source (NPS) pollution control and to calculate the presence of the first-flush. This review of literature offers certain components based on a detailed study conducted by Bertrand-Krajewski et al. (1998) and proposes a hypothesis for easy handling of the 'first-flush phenomenon'.

Gupta and Saul (1996) developed site-specific regression connections to guess the first-flush load of suspended solids in joined sewer flow using multiple stepwise linear regression technique. The maximum rainfall intensity, rainfall duration, maximum inflow and forerunning dry weather period were recorded to be the utmost significant parameters affecting the first-flush load of suspended solids. Sakrabani et al. (2009) reported biodegradability of organic substance, related to sewer residues during the first-flush. Oxygen uptake rate results specified that the maximum biodegradability was associated with the preliminary part of a storm event. Storm runoff pollution process was investigated by $\mathrm{Li}$ et al. (2007) in an urban catchment with an area of $1.3 \mathrm{~km}^{2}$ in Wuhan City of China. The outcomes indicated that the pollutant concentration peaks were preceding the peak flows in all of the eight monitored storm events.

In the Upper Silesian Coal Basin, Gzyl and David Banks (2007) conducted a case study of Grodziec and Siersza mines for the 'first-flush' phenomenon. They illustrated that to explain the observed concentrations of sulphate in the first-flush, amounts of leachable sulphur in the abandoned workings of $0.02-0.03 \%$ were enough. The runoff from four dissimilar copper roof surfaces was scrutinized by Athanasiadis et al. (2010) in fieldwork in order to detect the presence of the first-flush effect along with its effects. A reasonable first-flush effect concerning the spreading of copper mass in the roof runoff was found in almost $40 \%$ of all sampled precipitation events. To simulate the erosion from an organic in-pipe deposit, a previously developed numerical 


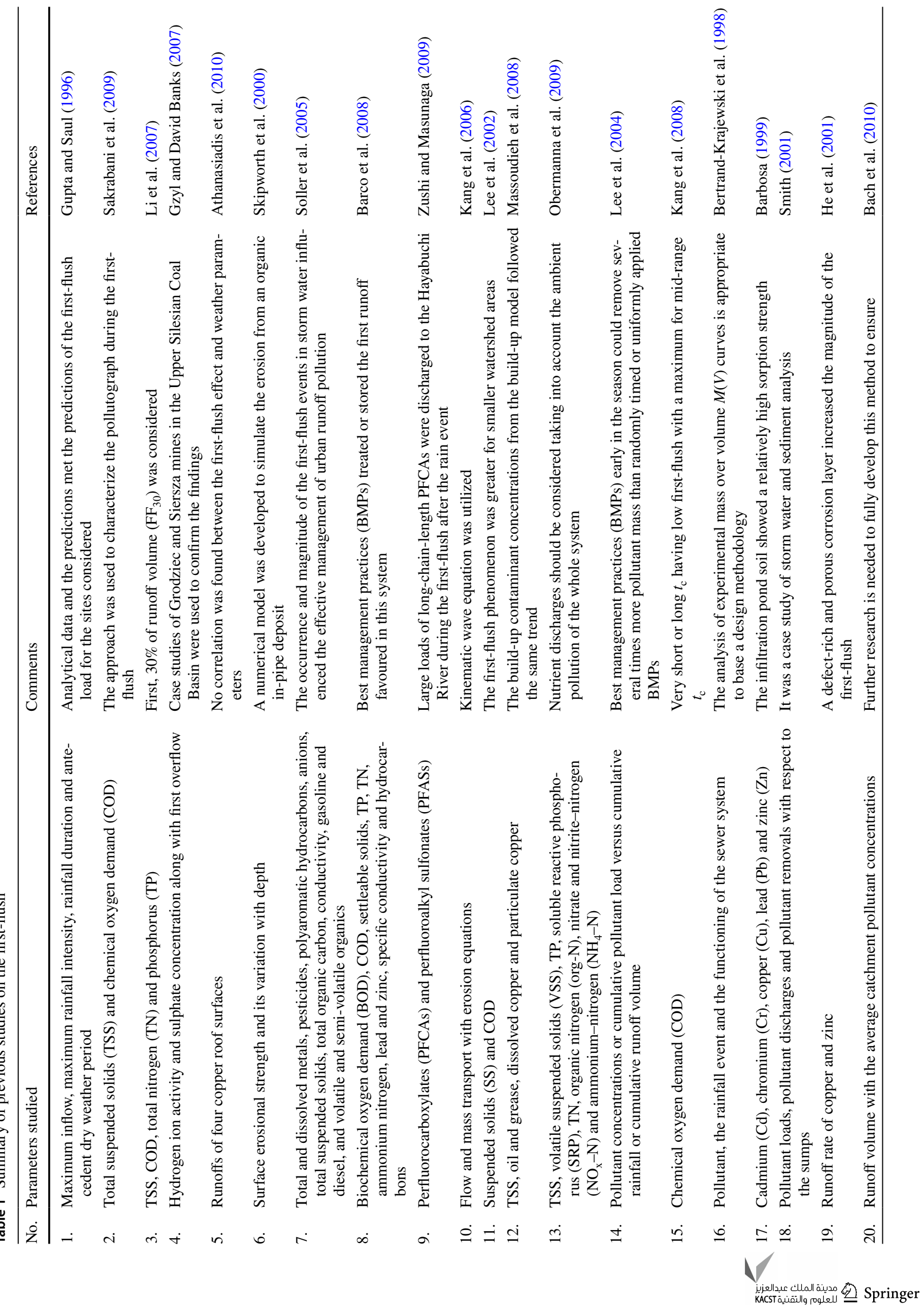




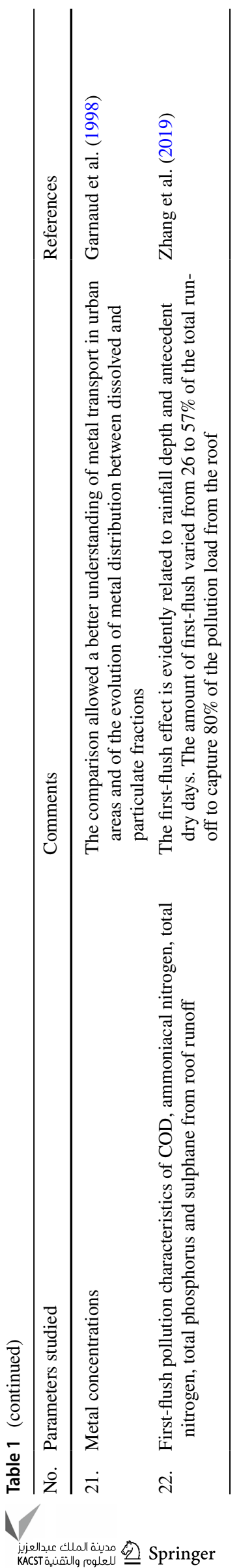

model was used by Skipworth et al. (2000) and physical factors that control the first foul flush in joint sewers were investigated. Systematic adjustments of physical parameters indicated that the precise characterization of bed properties, i.e. the surface erosional strength and its variation with depth, was more significant than the precise explanation of the improved hydraulic condition. How the characteristics of the first-flush events in storm water may influence the effective management of urban runoff pollution was investigated by Soller et al. (2005). From this study, the implication for urban runoff management was that if dissolved metals are to be addressed primarily, improvement of present control strategies is required to minimalize pollutant mass from storms that have an extended antecedent dry period. In northern Italy, polluted first-flush was examined by Barco et al. (2008) in an urban catchment having an area of 12.7 ha and drained by a combined sewer network. The investigation showed that to treat the peak amount of the initial portion of the runoff is better than to treat a constant flow rate.

Zushi and Masunaga (2009) launched fixed-point hourly monitoring in the river during a storm event to study the impact of first-flush using an automatic sampler. This investigation demonstrated that a substantial mass of long-chain perfluoro carboxylates (PFCA) is put off to the Hayabuchi River during the first-flush phenomenon. Kang et al. (2006) developed a deterministic model to describe pollutant mass flow and to use it to have a better design of best management practices (BMPs) to treat the first-flush. An optimum watershed size was discovered in the study to maximize the first-flush. Thirteen individual urban watersheds were monitored by Lee et al. (2002), which were representing unique types of suburban and industrial areas, together with other catchment properties. The effect of the first-flush was found profuse for few pollutants (e.g. SS) and less prominent for others (e.g. COD). A mechanistic model was developed by Massoudieh et al. (2008) to predict the highway runoff pollutographs. It was reported that the pollutant removal rate might not be proportional to the contaminant concentration accumulated on the land and building surfaces.

The characteristics and significance of the first-flush from agricultural areas have been studied by Obermanna et al. (2009). A concept of nutrient release from the study area has been introduced by them for conditions, where the firstflushes are crucial for rivers. They also suggested that the pollution of the total catchment should be considered. Lee et al. (2004) analysed four major data sets in wet seasons in order to study the presence of a seasonal variation in the first-flush phenomenon. The results revealed that applying BMPs at the beginning of the wet weather could efficiently remove more amount of pollutants, compared to uniformly applied or randomly timed BMPs. Kang et al. (2008) performed simulations to investigate the relationships between the first-flush $(\mathrm{FF})$ and the time of concentration $\left(t_{\mathrm{c}}\right)$ by using 
a one-dimensional kinematic wave model. They showed a non-monotone relationship, with very short or long $t_{\mathrm{c}}$ having a low first-flush ratio with a maximum for mid-range $t_{\mathrm{c}}$. Pollutant mass distribution against the volume of stormwater runoff and the first-flush were investigated by Bertrand-Krajewski et al. (1998), in which $M(V)$ curve analysis was used. The experimental $M(V)$ curves analysis took into account the intrinsic variability of the first-flush phenomena and appropriated the design methodology.

Barbosa (1999) monitored the highway runoff where a relatively high sorption strength was observed for the infiltration pond, implying that infiltration system is good for treating runoff pollution. A study on typical pollutants in stormwater sumps in an urban catchment was presented by Smith (2001). This investigation was a primary step towards developing an NPS pollution management model for stormwater sumps that includes hydraulic behaviour for assessing flow, pollutant loads and pollutant removals. Bach et al. (2010) introduced a method to assess the runoff volume with the mean pollutant concentrations against a certain increase in runoff amount, which employs the use of a number of event pollutographs. The sensitivity of runoff increment and the significance level was reported negligible. Four sites were studied by Garnaud et al. (1998) for different periods in a year within the Paris conurbation at the catchment outlets. The comparisons presented an improved understanding of the metal pollution process in the cities.

\section{Analysis of the first-flush curves}

The most widely used method of identifying the existence of the first-flush is the plot of pollutant mass $(M)$ against runoff volume ( $V$ ) as described by Bertrand-Krajewski et al. (1998). This is considered as one of the fundamental concepts of defining or identifying the first-flush phenomenon in a drainage system. According to this concept, the distribution of the pollutant mass $(M)$ flow for a storm event in drainage systems is interpreted by two curves: (1) the hydrograph $Q(t)$ and (2) the pollutograph $C(t)$ for any pollutant, where $Q$ is the runoff rate $\left(\mathrm{m}^{3} / \mathrm{s}\right)$ and $C$ is the pollutant concentration $(\mathrm{mg} / \mathrm{L})$. For a particular drainage area, the curves may differ from one rainfall event to another. These variations depend on various factors, e.g. variation in the rainfall intensity $I(t)$, characteristics of the catchment, inter-event dry period, amount of dry deposit, the condition of the drainage system, pollutant build-up, type of pollutant, etc. To analyse the first-flush occurrence, a curve is plotted showing the ratio of cumulative pollutant amount to the total pollutant, with respect to the ratio of cumulative runoff amount divided by the total runoff (Bertrand-Krajewski et al. 1998). If there are $n$ measurements of flow rate $Q_{i}$ and concentration $C_{i}$, time interval $\Delta t_{i}$, and assuming that $Q$ and $C$ vary linearly between two measurements, the following $M$ relation (Eq. 1) can be established, which can be plotted as shown in Fig. 2:

$\frac{\sum_{i=1}^{j} C_{i} Q_{i} \Delta t_{i}}{\sum_{i=1}^{n} C_{i} Q_{i} \Delta t_{i}}=f\left(\frac{\sum_{i=1}^{j} Q_{i} \Delta t i}{\sum_{i=1}^{n} Q_{i} \Delta t_{i}}\right)=f\left(\frac{\sum_{i=1}^{j} V_{i}}{\sum_{i=1}^{n} V_{i}}\right)$

where $n$ is the number of data, $j$ is the index from 1 to $n$ and $V_{i}$ is the discharged volume during the time interval $\Delta t_{i}$. In the past, such $M$ curves were used by other authors (Philippe and Ranchet 1987; Geiger 1984; Helsel et al. 1979).

\section{Variability of the first-flush curves}

Once the receiving water quality target is determined, the required capture of pollutant mass for treatment is to be estimated (Bertrand-Krajewski et al. 1995). The $M$ curve gives the runoff volume to be treated, in order to achieve the desired quality of the stormwater. For instance, in Fig. 2, to intercept $80 \%$ of the pollutant load, it is required to catch $60 \%$ of the runoff for the rainfall event 1 and $86 \%$ of the runoff volume for the rainfall event 2 .
Fig. 2 Variation in the firstflush curve (double-storey terrace houses in Malaysia)

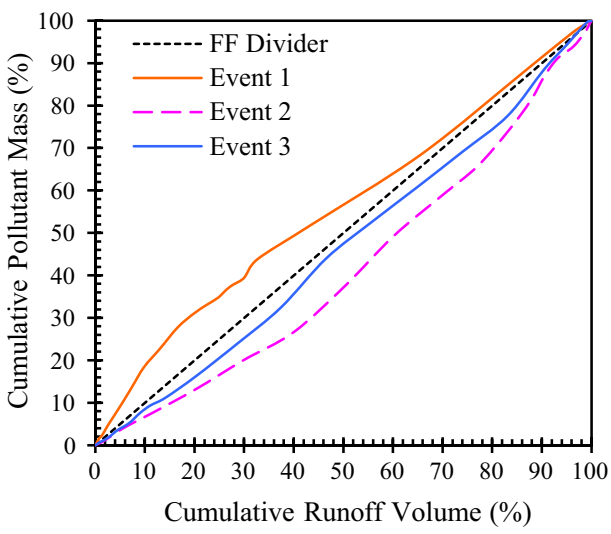

(a) Same Pollutant (BOD) Different Events

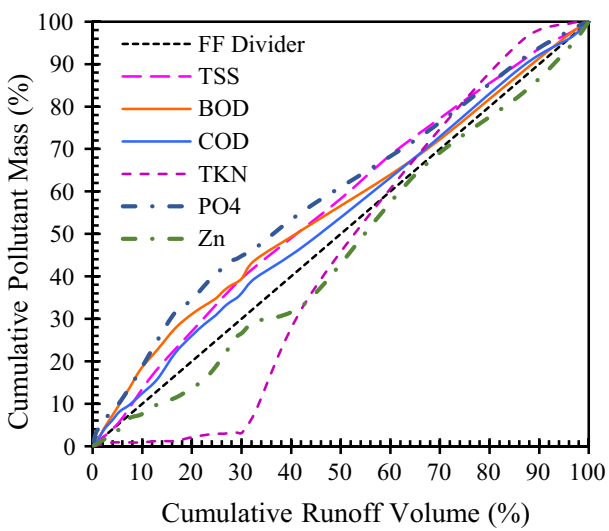

(b) Same Event Different Pollutants

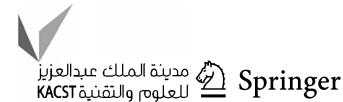


Observations conducted in many drainage systems in the developed countries show that $M$ curves vary significantly (Bertrand-Krajewski et al. 1998). A site-specific statistical method is required to interpret the variability of the firstflush phenomena. The set of all $\mathrm{M}$ curves for an individual drainage system and one pollutant may exhibit a wide variation (Bellefleur 1994; Saget and Chebbo 1994; EPA 1993; Menacher and Augustin 1992). This scatter curve is difficult to convert into one unique median curve as shown in Fig. 3 (Bertrand-Krajewski et al. 1998).

\section{Numerical analysis of the first-flush curves}

Bertrand-Krajewski et al. (1998) proposed that the numerical analysis and strength of the first-flush could be approximately done with a power function (Philippe and Ranchet 1987),

$F(X)=X^{b}$

where $X \Psi[0,1], F(0)=0$ and $F(1)=1$. To calculate the parameter $b$, six separate drainage systems and six combined drainage systems were sampled for 197 storm events (Saget and Chebbo 1995), which are available in the French database QASTOR (Saget 1994) The ' $b$ ' value of TSS for the separate drainage systems is presented in Fig. 3.

\section{Factors that affect the first-flush occurrence}

\section{Characteristics of the catchment}

No general relationship was found between the values of the parameter $b$ and the surface slope of the catchment, based on studies of 12 sites from the QASTOR database (Saget 1994). For areas varying from 7.6 to 4600 ha and slopes ranging

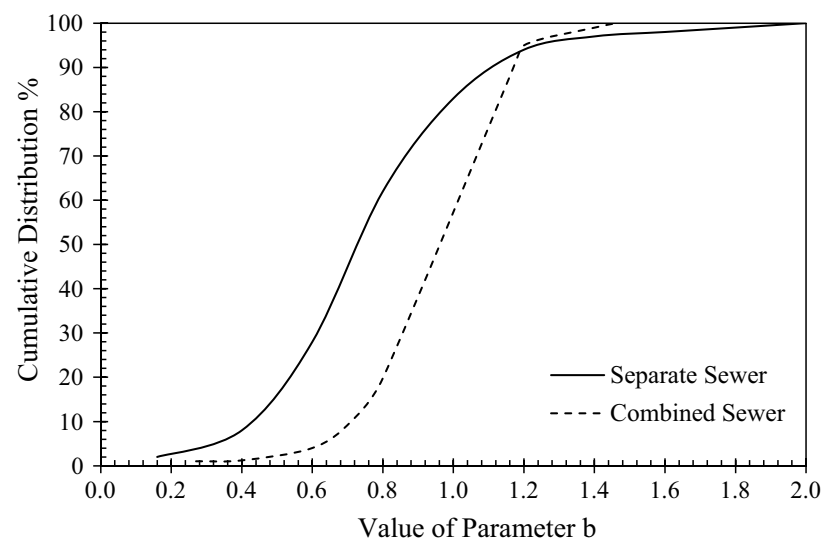

Fig. 3 Cumulative distribution of parameter $b$ for the $M$ curves for TSS (Bertrand-Krajewski et al. 1998) from 0.5 to $6.5 \%$, no significant relationship was determined. The value of $b$ varies for identical ranges of large and small areas and for basins having a mild or steep slope. The value of $b$ varies from 0.24 to 2.07 for TSS and from 0.27 to 1.40 for COD based on measurements taken from a highway system of 1.3 ha (Herremans et al. 1995).

\section{Features of the drainage system}

Similar to the watershed slope, the slope of the drain also is not an important factor. The lower values of $b$ are not related to any particular slope values. The low values of $b$ can be clarified with deposit erosion during rainfall events and the resultant first-flush phenomenon, which is often related to the drainage slope. However, the complexity of the phenomena is increased due to the contradictions reported in the literature and also because of the failure to explain the value of $b$ by one single parameter. One concept is that the first-flush occurs very often in drainage systems with a steep slope. The other idea is that it happens more frequently if erodible deposits are present in the drainage, which happens with a mild slope or with small flow rate drainage systems (Geiger 1987; FNDAE 1988; EPA 1993). These two conflicting criteria reveal that it is very difficult to estimate the values of $b$ with respect to the slope of the drainage system (Menacher and Augustin 1992).

\section{Characteristics of rainfall events}

Duration of the antecedent dry period, depth of rainfall, the highest rainfall intensity over 5 min were not found to be commonly related to the parameter ' $b$ ' (Saget 1994). Some variable relationships were observed occasionally for some watersheds. These findings are consistent with the results of Geiger (1984) according to which there is no type or a form of storm event that tends to have low or high values of $b$. However, $M$ curves can be closer to the bisector (the first-flush divider in Fig. 2) for hyetographs having several successive peaks compared to the case of simple single-flowpeak hyetographs (Menacher and Augustin 1992).

The relationship between the first-flush and length of the antecedent dry period has been described weak by Geiger (1987). On the other hand, Saget and Chebbo (1995) observed that when high rainfall and antecedent dry periods happen together, it tends to lower the value of ' $b$ '.

\section{Inadequacies in the first-flush definitions}

Several definitions of the first-flush are cited in the literature, which is already mentioned in Introduction of this paper. Even though many authors are using the same term the 
'first-flush', the definitions have distinct meanings from one another, which creates an indecisive situation.

Two main aspects have been considered by BertrandKrajewski et al. (1998) to analyse the past first-flush criteria:

- Clear expression and quantification of the first-flush phenomenon;

- Interception of the contaminant mass, as this is the most important element for the first-flush definition.

\section{Assessment of the 30:80 first-flush frequency}

According to this concept, the $M$ curves make it possible to also calculate the frequency of 30/80 first-flush. This is explained by the ratio of the number of curves having a first-flush to the total number of curves detected during a period of more than 6 months, for a certain catchment and an assembly of a representative set of curves and to estimate the first-flush frequency. By analysing runoff data from 662 storm events from the combined drainage system in Germany, Geiger (1984) demonstrated that a first-flush defined by an $M$ curve and the bisector (the first-flush divider in Fig. 2), occurred for TSS $25 \%$ of the rainfall events for TSS and for other pollutants $15 \%$.

\section{New definition of the first-flush phenomenon}

A new technique has been proposed by Bach et al. (2010) to detect the first-flush event. This new technique involves the following steps:

1. Determining the runoff increment depth, which is called the slice size, and analysing the event with respect to the slices.

2. Estimating the mean concentration of pollutants for each slice.

3. Constructing box and whisker plots for each slice to characterize each slice with respect to the distribution of mean pollutant concentration.

4. Categorizing the slices of similar characteristics.

5. Detecting the first-flush by determining the initial and background concentration of the catchment.

The background concentration refers to the concentration of the last group of slices if arranged in descending order. A first-flush is absent if all the slices can be merged in a single group. On the other hand, if there are different groups of slices, a first-flush occurrence is present.

However, in this new technique, a new term 'background concentration' has been introduced, though the significance of this term is not clear. The background concentration of a particular catchment can be higher than that of the desired water quality. Again, to reach the background concentration, it might require $90 \%$ or more of the runoff volume, which will yield no practical application of the term. Furthermore, slices of the same group might come from a different period of time during an event. If so, then it is required to have a tool to determine the temporal distribution of the slices so that the required runoff portion with respect to time should be treated. However, this tool is missing in this analysis technique, and this method is difficult to apply for BMPs design and operation.

\section{Recommendations for further investigation}

Earlier in the paper, factors affecting the first-flush occurrence have been discussed, which revealed that there are conflicts among the various studies regarding the first-flush. Therefore, it is anticipated that some other factors are also responsible, which have been neglected in the past studies. To have more reliable results, it is necessary to accumulate all the data that are likely to affect the first-flush occurrence, especially the relationship of the first-flush with the catchment area and runoff depth. Based on the experience of the authors, it seems to be logical and practical to capture first $20 \mathrm{~mm}$ of runoff as an easy-to-implement step towards the control of nonpoint or diffuse pollution from various landuses. We propose the following hypotheses to be explored so that the first-flush occurrence can be understood more rigorously but easily applied.

\section{Landuse}

In the previous studies, many have talked about the antecedent dry period, but no one has ever mentioned about the landuse within the study catchment. We propose that pollutant build-up is a function of antecedent dry period and also housekeeping within the landuse. Catchments having a larger proportion of lands where anthropogenic activities are rampant, e.g. construction sites, commercial areas, are likely to build up the pollutants rapidly. Therefore, even with short antecedent dry weather period, pollutant build-up might be higher than a catchment having less anthropogenic activities.

\section{Catchment roughness}

A catchment having higher roughness is hypothesized to retain a portion of the washed-off pollutants before being discharged into the stream. So, the first-flush occurrence is less likely to happen in these cases. On the other hand, wash-off will be higher for a less rough catchment and less likely to retain pollutants, yielding a high concentration of contaminants at the beginning of the rainfall-runoff process. 


\section{Shape of the catchment}

The shape of the catchment has an influence on the runoff hydrograph, which in turn influences the nature of the NPS pollution generated from the catchment area and its firstflush characteristics. Square-shaped catchment will have more likeliness to have strong and confirmed first-flush phenomenon compared to elongated and irregular-shaped catchments.

\section{Drainage density}

Drainage density and type of drains are also important factors in the occurrence of the first-flush effects. A catchment with well-organized and high-density drainage system is more likely to generate confirmed and stronger first-flush phenomenon compared to a catchment area with fewer drains.

\section{Catchment cleanliness}

It is really difficult to measure the overall cleanliness of a catchment. However, an urban catchment in a developed country is supposed to be cleaner than a rural catchment or an urban catchment in an undeveloped country. An already cleaned environment is supposed to yield almost constant pollutant concentration when washed off, meaning that firstflush is less likely to happen. The opposite is hypothesized to be true for a dirty catchment.

\section{Simplistic approach to control the effect of first-flush}

Based on the published work, there is no doubt that the initial portion of the storm runoff carries a high concentration of pollutants compared to the later part of the runoff. However, despite a good amount of research conducted, the question and uncertainty still exist as how much (volume or depth) of the first-flush should be captured from each drainage system, in order for the BMPs to be cost-effective, optimized and efficient. As the main idea of the first-flush concept is to make the NPS pollution mitigation efficient and cost-effective, a simplistic approach or hypothesis could be tested for further study and investigation. As it is evident that uncertainty and ambiguity exist in the occurrence of the first-flush in the drainage system (due to various factors such as topography of the catchment, nature of the drainage system and types of pollutant), a simple guideline could be followed to overcome the challenges and uncertainties related to the first-flush phenomenon.

The main objective of the simplistic approach would be to capture a reasonable amount of runoff from the drainage system for each catchment area. For instance, in order to make the NPS pollution control programme easy and effective, the first-flush of $20 \mathrm{~mm}$ runoff can be captured for any size of the drainage system, which would result in $200 \mathrm{~m}^{3}$ of runoff volume to be captured and treated using the suitable BMPs. The total areas to be required for the first-flush control BMPs would be within $0.5-1.0 \%$ of the total catchment area (depending on the type and combinations of the BMPs). Such simplistic approach would help the authorities of the developing and developed countries reduce NPSrelated pollution, where the NPS pollution is a serious but unattended or less attended concern. Adopting such simple approach (instead of current practice of chasing the storm events, conducting risky sampling, paying for costly testing and painstaking analysis), the control of NPS pollution can be achieved at fewer difficulties and the approach would also be easy to implement compared to going through the arguments and justification required to establish the existence or absence of the first-flush in the drainage system.

\section{Conclusions}

The published works on the first-flush concept of runoff pollution control are reviewed in this paper. The first-flush phenomenon is a potent measure for sorting on-site treatment facilities involving typical small catchments. Although isolation and capture of storm runoff from the first-flush is considered as a useful measure in controlling nonpoint source (diffuse) pollutions, some problems still prevail when controlling pollutions in catchments with an area larger than 10 ha. This paper reveals the inefficiency of the treatment system when a large volume of storm runoff is captured from large catchments. Therefore, certain factors such as the shape and sizes of the catchment, rainfall duration and intensity of the storm event and the capacity of the drainage system need to be considered to isolate first-flush from the total runoff. It is also suggested to investigate the effect of land cover, landuse, roughness and cleanliness of the catchment on the occurrence of first-flush. Additional studies are required to determine the optimum runoff depth that should be captured to make the treatment of the first-flush costeffective. As a hypothesis, this paper recommends interception of $20 \mathrm{~mm}$ runoff depth as a typical limit for the effective first-flush capture to reduce the nonpoint source from urban areas. Field studies need to be conducted to validate the hypothesis proposed in this paper.

\section{Compliance with ethical standards}

Conflict of interest The authors declare that there is no conflict of interest in the publication of this article. 
Open Access This article is licensed under a Creative Commons Attribution 4.0 International License, which permits use, sharing, adaptation, distribution and reproduction in any medium or format, as long as you give appropriate credit to the original author(s) and the source, provide a link to the Creative Commons licence, and indicate if changes were made. The images or other third party material in this article are included in the article's Creative Commons licence, unless indicated otherwise in a credit line to the material. If material is not included in the article's Creative Commons licence and your intended use is not permitted by statutory regulation or exceeds the permitted use, you will need to obtain permission directly from the copyright holder. To view a copy of this licence, visit http://creativecommons.org/licenses/by/4.0/.

\section{References}

Athanasiadis K, Horn H, Helmreich B (2010) A field study on the firstflush effect of copper roof runoff. Corros Sci 52:21-29

Bach PM, McCarthy DT, Deletic A (2010) Redefining the stormwater first flush phenomenon. Water Res 44(8):2487-2498

Barbosa AE (1999) Highway runoff pollution and design of infiltration ponds for pollutant retention in semi-arid climates. Ph.D. Thesis, Environmental Engineering Laboratory, Aalborg University, Denmark, ISBN 87-90033-19-1

Barco J, Papiri S, Stenstrom MK (2008) First-flush in a combined sewer system. Chemosphere 71:827-833

Bellefleur D (1994) New techniques for storm overflows. Technical Seminar on Storm Overflows, Lyon (in French)

Bertrand-Krajewski JL, Brelot E, Chocat B, Tabuchi JP (1995) A strategy for controlling stormwater discharges. TSM 90(11):815-820 (in French)

Bertrand-Krajewski JL, Chebbo MG, Saget A (1998) Distribution of pollutant mass vs volume in stormwater discharges and the firstflush phenomenon. Water Res 32(8):2341-2356

EPA (1993) Manual for combined drainage overflow control. In: EPA report or EPA/625/R-93/007. Environmental Protection Agency (EPA), Cincinnati

FNDAE (1988) Stormwater tanks in drainage systems. In: FNDAE (Fonds National pour le Développement des Adductions d'Eau in French: National Fund for the Water Supply Development) Technical Report No. 6. Paris, France (in French)

Garnaud S, Mouchel J-M, Chebbo G, Thevenot DR (1998) Heavy metals concentrations in dry and wet atmospheric deposits in Paris district: comparison with urban runoff. Sci Total Environ 235:235-245

Geiger WF (1984) Characteristics of combine drainage runoff. In: Proceedings of the 3rd international conference on urban storm drainage. Goteborg, Sweden, pp 851-860

Geiger WF (1987) Flushing effects in combined drainage systems. In: Proceedings of the 4th international conference on urban storm drainage. Lausanne, $\mathrm{p} 46$

Griffin DM Jr, Grizzard TJ, Randall CW, Helsel DR, Hartigan JP (1980) Analysis of non-point pollution export from small catchments. J Water Pollut Control Fed 52(4):780-790

Gupta K, Saul AJ (1996) Specific relationships for the first-flush load in combined sewer flows. Water Res 30(5):1244-1252

Gzyl G, David Banks D (2007) Verification of the "first-flush" phenomenon in mine water from coal mines in the Upper Silesian Coal Basin, Poland. J Contam Hydrol 92:66-86

He W, Wallinder IO, Leygraf C (2001) A laboratory study of copper and zinc runoff during first flush and steady state conditions. Corros Sci 43:127-146

Helsel D, Kim J, Grizzard T, Randall C, Hoehn R (1979) Land use influences on metals in storm drainage. J Water Pollut Control Fed 51(4):709-717
Herremans L, Montrejaud-Vignoles M, Roger S (1995) Non-existence of the stormwater first-flush example of a small highway catchment. In: Project of paper for the AGHTM "Stormwater" working group. Paris (in French)

Kang J, Kayhanian M, Stenstrom MK (2006) Implications of a kinematic wave model for first-flush treatment design. Water Res 40:3820-3830

Kang J, Kayhanian M, Stenstrom MK (2008) Predicting the existence of stormwater first-flush from the time of concentration. Water Res 42:220-228

Lee JH, Bang KW, Ketchum LH, Choe JS, Yu MJ (2002) First-flush analysis of urban storm runoff. Sci Total Environ 293:163-175

Lee H, Lau S, Kayhanian M, Stenstrom MK (2004) Seasonal firstflush phenomenon of urban stormwater discharges. Water Res 38:4153-4163

Li LQ, Yin CQ, He QC, Kong LL (2007) First-flush of storm runoff pollution from an urban catchment in China. J Environ Sci 19:295-299

Mamun AA, Latiff NA, Salleh MN (2014) Characterization of storm runoff quality from a highway in Selangor and conceptual design of constructed wetland. Adv Environ Biol 8(3):810-814

Massoudieh A, Abrishamchi A, Kayhanian M (2008) Mathematical modeling of first-flush in highway storm runoff using genetic algorithm. Sci Total Environ 398:107-121

Menacher F, Augustin A (1992) Detention in combined drainages. In: Institute for Sanitary Engineering, University of Karlsruhe, Germany, Report No. 64 (in German)

Novotny V, Olem H (1994) Water quality, prevention, identification and management of diffuse pollution. Van Nostrand Reinold, New York

Obermanna M, Rosenwinkel K, Tournoud M (2009) Investigation of first-flushes in a medium-sized mediterranean catchment. J Hydrol 373:405-415

Philippe JP, Ranchet J (1987) Pollution des eaux de ruissellement pluvial en zone urbaine, synthèse des mesures sur 10 bassins versants en région parisienne. LCPC No. 142, 76 p (in French)

Saget A (1994) Data base on stormwater quality: distribution of discharged pollutant loads and sizes of interception constructions. $\mathrm{Ph} . D$. Thesis. Paris, France, 333 (in French)

Saget A, Chebbo G (1994) Analysis of pollutant mass distribution in stormwater discharges. CERGRENE/Lyonnaise des Eaux report, $96 \mathrm{p}$ (in French)

Saget A, Chebbo G (1995) Distribution of pollutant loads during rainfall events. CERGRENE (Centre d'Enseignement et de Recherche pour la Gestion des Ressources Naturelles et l'Environnement) Lyonnaise des Eaux report, June 1995, 60 (in French)

Sakrabani R, Vollertsen J, Ashley RM, Hvitved-Jacobsen T (2009) Biodegradability of organic matter associated with sewer sediments during first-flush. Sci Total Environ 407:2989-2995

Skipworth PJ, Tait SJ, Saul AJ (2000) The first foul flush in combined sewers: an investigation of the causes. Urban Water 2:317-325

Smith E (2001) Pollutant concentrations of stormwater and captured sediment in flood control sumps draining an urban watershed. Water Res 35(13):3117-3126

Soller J, Stephenson J, Olivieri K, Downing J, Olivieri AW (2005) Evaluation of seasonal scale first-flush pollutant loading and implications for urban runoff management. J Environ Manage 76:309-318

Torno HC (1984) The EPA nationwide urban runoff program (NURP). In: Proceedings of the 3rd international conference on urban storm drainage. Goteborg, pp 4-8, 1465-1474

Vorreiter L, Hickey C (1994) Incidence of the first-flush phenomenon in catchments of the Sydney region. Natl Conf Publ Inst Eng 3(94/15):359-364 
Zhang W, Zhang X, Fan J et al (2019) Runoff pollution characterization and first flush effect of urban roof catchment. Desalin Water Treat 119:262-266

Zushi Y, Masunaga S (2009) First-flush loads of perfluorinated compounds in stormwater runoff from Hayabuchi River basin, Japan served by separated sewerage system. Chemosphere 76:833-840
Publisher's Note Springer Nature remains neutral with regard to jurisdictional claims in published maps and institutional affiliations. 